\title{
SECTION OF SURGERY.
}

\section{ESTHLANDER'S THORACOPLASTIC OPERATION.}

\author{
By Sir WILliaM STOKES, Ch.M. Univ. Dob., F.R.C.S. ;
}

Surgeon-in-Ordinary to Her Majesty in Ireland;

Professor of Surgery, Royal College of Surgeons.

[Read in the Section of Surgery, November 11, 1892.]

Among the recent developments of operative surgery applicable in so many instances to regions until lately considered as belonging mainly to the province of the physician, those relating to the surgery of the thorax must be considered as occupying a foremost place.

From what $I$ have experienced in my own practice, and seen in that of others, the conviction has been forced on me that in thoracic surgery we are only, so to say, commencing to tread what is as yet but a dimly lit, and to a great extent unexplored, path; one, however, destined to lead, notwithstanding many probable failures and disasters in the future, to far greater achievements than have hitherto been accomplished by even the most conscientious and skilful surgeons. On the present occasion, however, I desire to confine myself mainly to thoracoplastic treatment of chronic purulent effusion within the pleura-a condition which has so often proved a causal factor of serious secondary mischief, not only in the lungs, but in the brain and other organs, and the successful treatment of which has, as a rule, been found so difficult of accomplishment. 
The causes that have been mainly instrumental in enabling us to get more frequently than formerly, successf ul results in the treatment of empyema arise not only from the adoption of antiseptic practice, but also to carrying out a more thorough and methodical system of drainage. This is especially true in connection with comparatively recent empyemata; but in the chronic fistulous forms of the disease, such as those $I$ am about to draw attention to more particularly, drainage, however carefully and skilfully employed, is not, as a rule, sufficient, though often found to be so in recent ones. I believe the principal reason for this is, that in the latter, the expansile power of the lung though impaired is not lost, and also that the chest walls have not, as regards their natural elasticity, been seriously affected.

If, however, the empyema be of long standing the visceral pleura will become, as a rule, greatly thickened, lose its elasticity, and cease to respond to the lung pressure. Under these circumstances there is an adaptation on the part of the walls of the cavity to its lessened contents by a falling in of the chest wall, and a simultaneous ascent of the diaphragm, combined or aided perhaps by the copious formation of granulation tissue. But there is a limitation to both these actions, and especially in the case of the chest wall, the elasticity of which, owing to long-continued pressure from within, becomes markedly diminished. It is in this condition of things that the surgeon can in many instances so effectively supplement the efforts nature has made to obliterate the cavity.

In considering the subject, therefore, we must distinguish between the cases calling for removal of a portion of one rib to facilitate a thorough drainage of an empyema, and those that call for the performance of what is distinctly a plastic operation, such as Esthlander's, rendering necessary the removal of portions of several ribs to enable the thoracic wall to fall in and obliterate the cavity formed by insufficient 
expansion of the lung on the affected side, and the diminished elasticity of the thoracic parietes. It is to the latter class of case that I wish more particularly to draw attention, being one which, in consequence of the probable supervention of the serious conditions likely to follow long-continued suppuration, such as serious visceral disease, acute tuberculosis, septicæmia, cerebral abscess, \&c., is of the utmost gravity, and likely to arise if steps be not taken to arrest or check the purulent secretion.

The first case I would draw attention to was that of a man, aged forty-six, Jeremiah Sullivan by name, who was admitted into the Meath Hospital, under my care, on the 10th of June, 1890. He was a native of Kerry, and a farmer by occupation. His sufferings dated from a period four years previously to his admission into hospital. He stated that at that time, after getting greatly heated from some work in a forge he walked a considerable distance home, the weather being very cold and damp at the time. This was followed by a severe cold, accompanied by a great pain in the left side, violent cardiac palpitation, which he referred to the right side, and great weakness. Notwithstandingr these troubles no medical or surgical advice was sought for. There was evidently a subsidence of the graver symptoms he had at first, and things remained in a quiescent state for over two years. He then noticed what he termed a "lump" on the left side below and to the left of the nipple. Poultices were applied, and ultimately it-the tumour or lump-burst, when, he said, " about a quart of yellow matter came away.' The discharge continued oozing through the opening, sometimes profusely, and at other times in small quantities, until March, 1890; at that time the sinus closed, and remained so for about ten weeks. It then, however, re-opened, the discharge being then more prof use than before, and differing from what it formerly was in consistence and colour, being 
much thinner, or more watery, and of a greenish-yellow tint. The patient had shortly before this become much emaciated, having lost, as he said, "all his weight." On his admission he had an anxious, drawn, haggard expression, was very anæmic and thin. The left side was rather flat compared to the right, over the left base was loss of vocal fremitus, and from the fourth intercostal space downwards complete dulness on percussion. The circumferential measurement on the right side at the nipple was $18 \frac{1}{2}$ inches, and on the left 17 inches, and the same difference was observed on measurements being taken $3 \frac{1}{2}$ inches lower down. Three small openings close together in the 10th intercostal space, in the middle axillary line, were observed, from which a thin, sanious, purulent discharge exuded at each inspiration. The heart sounds were normal, but very weak. Having regard to the age of the patient, the great chronicity of the trouble, and the weak and emaciated condition of the patient, the case could not be looked upon as one favourable for any operative interference, but still, I deemed it one on which Esthlander's operation might exercise a beneficial influence, and possibly be a means of saving, or at least prolonging, his life. Accordingly, on June 20th, I made by a lunaterl incision a large oval-shaped flap. I exposed the bodies of the 5 th, $6 \mathrm{th}, 7 \mathrm{th}$, and $8 \mathrm{th}$ ribs, and portions of each of them having been carefully denuded of periosteum by Ollier's raspatory were removed, which was accomplished without difficulty, the membrane being thickened and loosely applied to the bone. The bones were divided by fine resection saws, and partly by forceps.

A free opening was now made in the pleura, which was much thickened, and a large quantity of thin unhealthylooking pus was evacuated. I then thoroughly washed out the cavity with a warm bichloride of mercury solution, and a full-sized drainage-tube was left in the wound. 
It is unnecessary to give the daily reports of the case after the operation, but on July 10th the report is "the patient looks bright and strong, has a good appetite, and sleeps well. 'The openings have now altogether disappeared." On July 14th the report states there was "no discharge," and the same report on the 17 th. Shortly after this, the patient being practically convalescent, I left town for some weeks, and during my absence I was grieved to learn that my patient got a violent attack of choleraic diarrhœa, and notwithstanding that the most prudent and energetic measures were adopted by the resident surgeon, Dr. Newell, to check the disorder, the patient ultimately sank from exhaustion.

In the next case happily no untoward circumstance during convalescence such as that mentioned in the last one prevented ultimately a complete recovery being obtained. 'The case is in truth one of great importance, resembling in many respects the well-known one of Professor Schede, of Hamburg, which was exhibited at the International Medical Congress at Berlin, and which created so much interest.

Joseph Hill, aged forty-seven, a lighthouse keeper by occupation, and residing at Howth, was admitted under my care into the Meath Hospital, on September 14th, 1890, recommended to me by Dr. Doyle. On the previous January the patient had an attack of pleuritis on his left side. He recovered as he thought, but erroneously, for the pain continued, and for this blisters were applied, which apparently had the effect of relieving him temporarily at all events. Alout a month subsequently he noticed a swelling in his side just under the nipple, accompanied with great pain, which increased as the swelling grew larger. Poultices were applied for about six weeks. There were indications of a pulmonary fistula having formed, as occasionally large quantities of what he termed "thick creamy stuff" were 
discharged by the mouth. The patient then entered one of the hospitals in this city, where the swelling was punctured, and the patient stated-the statement probably being exaggerated-that "about five pints" of pus came out. He left the hospital in June and returned to Howtl, where he came under the care of Dr. Doyle. Poultices were applied at first, and subsequently the cavity was flushed with a weak carbolic solution, and antiseptic dressings were applied. Generous diet and a generally tonic treatment was recommended, and in the course of a month a marked improvement took place in the patient. The discharge, however, though much diminished in quantity, still continued, and Dr. Doyle, believing that surgical operative treatment was indicated, recommended him to my care. The patient on his admission was much emaciated and anæmic. At times he got paroxysm: of cough and the expectoration was distinctly purulent. He slept well and his appetite was fairly good. The circumferential measurement of the chest was 33 inches, the right half 17 inches, the left 16 inches. There was slight but still obvious dexio-cardia. His pulse was 100 , rising towards evening to 120 . At that time there was a corresponding rise in temperature, being in the morning practically normal, but rising towards night to between $10 \mathrm{~L}$ and $102^{\circ}$. There were no physical signs of any pulmonary tubercular mischief. The patient remained under observation and treatment until Oct. 1st, when I determined to operate. The patient being anæsthetised by chloroform, I exposed the ribs by a lunated incision, the centre of which was crossed by the mid-axillary line about three inches behind the previous opening. The flap was then dissected back and the ribs were found so closely approximated as almost to obliterate the intercostal spaces. Portions of four ribs were excised by a fine saw and bone forceps, the portions removed averaging $1 \frac{1}{4}$ inches in length, the periosteum, which 
was thickened and loose, having previnusly been detached from the bone with Ollier's raspatory and with great facility. A large quantity of pus was then evacuated and the carity thoroughly flushed with a warm boric solution. A full-sized drainage tube was then inserted into the pleural sac. and the edges of the wound brought together by carefully asepticised silk sutures. The patient got very cold and weak while on the operating table and coughed a good deal when the drainage tube was inserted. Iodoform dressings were applied, which at that time $I$ believed to be superior to any other; boracic acid being what I get the best results with now.

After the operation the progress of this patient to recovery though slow was uninterrupted. He left the hospital early in November free from all cough, materially increased in weight, appetite good, able to sleep well, and the wound and sinuses completely closed; he soon after was enabled to return to his duties as keeper of the lighthouse at Howth, a post which he still holds, and the responsible duties of which he efficiently discharges.

I have assisted my colleague, Sir P. C. Simyly, in three cases in which he performed Esthlandel's operation. Two of the patients were females, aged respectively twenty-five and twenty-eight years, and the third case was that of a boy, aged five years, who was operated on in the Meath Hospital in February, 1891. He had previously been under the care of a medical practitioner in the country, who treated him for pleurisy and tapped his left side, withdrawing thence a pint of pus. After a week the side filled again and it was poulticed. This treatment went on until October, when he began to cough up pus. In December, 1890, he was taken to Cork to be operated on, but owing to the excessive flow of pus from his mouth when the patient was turned over on the healthy side, in order to reach the situation where the operation was to be performed, it was not considered safe to 
proceed further, and, accordingly, it was determined to abandon operative interference. He was taken home, and shortly afterwards was sent up to Dublin for treatment. On February 6th Sir P. C. Smyly operated and removed substantial portions of two ribs, evacuated a large quantity of pus, and inserted a full-sized drainage tube. The same difficulty arose in reference to the escape of pus from the mouth threatening suffocation when the patient was turned over on the healthy side. This complication was obviated to a great extent by drawing the patient towards the edge of the table so that the affected side should be well over it, and the operator then getting below and behind the patient was enabled to carry out the steps of the operation withour turning him over on the sound side at all.

T'he drainage was kept up till February 26th, when the tube was removed, and shortly afterwards the wound closed. On March 20th the patient left the hospital perfectly well. No purulent expectoration was observed from the day the operation was performed. The boy has been in excellent health ever since.

An equally good and permanently good result was obtained in the case of one of the ladies operated on whom $I$ have previously alluded to. The symptoms in her case were of a very serious and alarming character. She was very emaciated, anæuic, and had profuse night sweats, and suffered greatly from purulent expectoration, and all the symptoms and signs of pleuritic effusion were present in " marked degree. The diagnosis of empyema was made, which was subsequently veritied by removing some of the contents by a hypodermic needle-an instrument which has so largely taken the place of the stethoscope in estimating the nature of these cases.

In this case portions of three ribs were removed, the pleural cavity flushed, and free drainage employed. The 
progress to recovery was very satisfactory, and her good health has been maintained ever since.

In the third case, which had many features in common with the last one, and which was operated on in a sinilar manner, the patient sufficiently recovered to be able to go to the Engadine, in Switzerland. About eight months after the operation, however, pyæmic symptoms unhappily were developed. Purulent deposits in the shoulder and other situations occurred, followed by symptoms of cerebral meningitis, which ultimately proved fatal.

There still exists much difference of opinion as to whether thoracoplasty should be regarded as only suitable, and in truth solely restricted to chronic fistulous empyemata, and the cases that have frequently been tapped or aspirated, or whether it should be arlopted, as in two of Sir Philip Smyly's cases, as a primary operation. The drift of surgical opinion judging from the writings of those, notably $\mathrm{Mr}$. P. Gould and Mr. Godlee, who have taken a special interest in this procedure, would point in the direction of confining the operation to those cases where what has been somewhat oddly termed the "rratural" cure of empyema has not been accomplished-viz., the one which it is alleged generally results from a drainage operation methodically carried out. Mr. Gould states that it is important to emphasise this, lest the success attending it should tempt the surgeon to perform the operation merely to save time. The severity of the operation is such that it is only justifiable when it is plain that it is demanded to save life.-(Lancet, Feb., 1888).

Instead of making such a sweeping declaration as to the cases suitable for this operation, and regarding it solely in the light of a dernier ressort, it would, I think, be preferable to base the discrimination of these cases on different lines. Although it is not possible as yet to publish any formidable statistics of the operation performed in this city, our 
experience, such as it is, amply justifies us in questioning decidedly the often-expressed view that it should be regarded in the light of a "forlorn hope" operation. The cases that have been operated on in Dublin, happily, as a rule, with such signal success, by our President, Sir P. C. Smyly, Mr. Kendal Franks, Mr. Swan, Mr. Thornley Stoker, Mr. Heuston, and myself, all forbid the adoption of so gloomy a view. On the contrary, the experience derived from these cases is of so encouraging a nature as to make one venture to predict that the operation will ultimately be deemed applicable to a larger range of cases than at present, and not be generally regarded merely as a supreme and final effort to save life fast ebbing away under the baneful influence of protracted suppuration, but rather as a means to prevent a condition of things which, once established, so of ten leads to a fatal termination. I think, therefore, that it is not premature to express the opinion, that in deciding on the applicability of the procedure in any particular case we should be guided largely by the consideration as to what was the length of time that had elapsed since the development of the empyema in all cases where it is possible to obtain accurate information on the subject. If. for example, the disease had lasted four or five months, a sufficient time to diminish the normal elasticity of the thoracic parietes and allow the pleura to become thickened, infiltrated, and lined with soft, spongy, easily bleeding granulation tissue, and have, perhaps, deposited on it a quantity of thick jelly-like coagulable lymph, and the fluid contents, as they often are, fotid, then I should say that drainage alone would probably be found insufficient, and the plastic operation be attended, as it hitherto has been in so large a number of cases, with satisfactory results. It must be remembered, too, that in hospital practice, at all events. it is the chronic cases that we are usually called upon to deial 
with. All hospital surgeons and physicians of experience know how frequently it happens that patients postpone seeking advice until the time has passed when a less hazardous operation than the one that has ultimately to be performed would have amply sufficed. Cases of empyema are not exceptions to this rule, and if the case be of long standing in which there is evidence of exhaustion from continued suppurative discharge through pulmonary or pleural fistula, thoracoplasty, after methodical exploration to determine the length, depth, and size generally of the cavity, on which will depend the number of ribs or portions of ribs to be removed, should then, I think, be performed without delay, and in the majority of cases will be attended with good results.

As regards the line of incision to make over the ribs to be excisech, various recommendations have been made. Esthlinder made a transverse incision over the centre of the intercostal space between two ribs to be removed. Jacobson has recommended two, three, or more flaps, each presumably of small size; $\mathrm{Mr}$. Gould a vertical incision in the centre of the cavity; and, lastly, the large oval flap method. In the cases I operated on I adopted the latter, the lower edge of the flap corresponding or nearly corresponding to the opening made subsequently for the drainage tube; but it seems to me that it is not a matter of very prime importance which of these lines of incision are selected, so long as we get the field of operation sufficiently clear and the osseous structure to be dealt with fully exposed. A more important point is to determine the situation where the opening into the pleural cavity should be made. Mr. Godlee recommends a point corresponding to the ninth rib and a little external to the angle of the scapula. Mr. Heuston suggests the eighth intercostal space slightly posterior to the scapular line. He bases this recommendation from experiments on subjects, 
finding that "in that position there is less danger of implicating the attachment of the diaphragm or opening into the abdominal cavity if the incision be made through the eighth intercostal space. In fact on the dead subject when opening into ninth intercostal space $I$ was never less than the breadth of a rib from the diaphragm, and consequently would have no hesitation in opening through the ninth space."

Although quite sensible of the signal advantages obtained by making the pleural opening in as depending a situation as possible, it must be borne in mind that the results of experiments of this kind alluded to, on subjects in which there was no evidence of previously existing pleural effusion may be misleading, and $I$ cannot but think that having regard to the way in which in chronic empyema the diaphragm is as a rule displaced or drawn upwards, that selecting situations for making the opening so low down as those recommended by Mr. Godlee and Mr. Heuston, would, in a large proportion of cases, be attended with some peril, for implication of the diaphragm could not be looked upon in any other light than as a calamity which, under the circumstances, could hardly be recovered from.

Another very important point in connection with this subject relates to the question of flushing the pleural cavity after evacuation of its purulent contents. Some surgeons are very apprehensive about doing this in consequence of deaths having occurred during injection. It is difficult to account for or explain the cause of such disasters. Happily in Dublin no case of the kind has, so far as $I$ am aware, occurred. In the cases I operated on, and in those I have assisted at, copious flushing was adopted both during and subsequent to the operation, and no symptoms ever arose that gave cause for any apprehension. In cases of large empyemata, where there is danger of weeping hæmorrhage into the cavity of the pleura, consequent on the sudden 
removal of pressure from the granulations, asepsis can harilly be anticipated if the numerous blood-clots specially liable to decompose are left in the cavity. Their removal, therefore, by copious and frequent flushing is a matter of prime importance, and what I think is best adapted for the purpose is a warm boric solution.

At the commencement of this communication I alluded to recent developments and advances in operative surgery. Among these Esthlander's operation will, I think, be accorded a foremost place, and be regarded as among the many kindly fruits that have come to us from the ever-extending and healthy growth of antisepsis, which has enabled us, under its beneficent, protecting, and of ten magical influence, to advance so far and accomplish so much, and the discovery and fostering of which must ever signalise the era in which we have lived and worked.

Mr. Heuston said that in the admirable paper of Sir William Stokes he had hit on the keynote in the treatment of empyemata when he stated that the method to be employed depended on the duration of the purulent effusion. To talk of any one method of treatment for all empyemata was quite irrational. In reference to Esthlïnder's operation, it was required only in cases of very long standing, where the conditions as mentioned by Sir W. Stokes existed, and gave rise to a space which could not be occluded unless the chest wall were allowed to adapt itself to the collapsed lung. In the performance of Esthliander's operation it was important that the periosteum of the rib should not be preserved to a great extent, as it was liable to form new bone to such an extent as to do away with the object of the operation. In the more recent cases operated on by Mr. Heuston he turned the flap of periosteum over the end of the rib where it had been cut across, and thus hindered the absorption of the discharge by the cancellous bony tissue, to which he ascribed the immunity of his patients from pyæmia, which some authors consider the greatest danger from this operation. Mr. Heuston expressed his thanks for the flatlering 
mention made of his paper, and in reply to Sir W. Stokes, wished to state that he never injured the diaphragm in the many operations he had performed, although he always selected the eighth interspace in the scapular line for his incision. This position presented a great advantage over those incisions made on the anterior or lateral chest wall, in the fact that here the ribs were so fixed by their vertebral attachments that there was not the danger of the tube being occluded by the ribs falling together, which $\mathrm{Mr}$. Thornley Stoker mentioned was so frequent in the cases where the incisions were made more anteriorly. The only point in Sir William Stokes's paper with which he (Mr. Heuston) was not, from his practical experience, inclined to agree, was in the utility of frequent washings of the pleural cavity; and always, in recent cases, he employed only one washing-viz., at the time of the operation, to remove any semi-solid lymph which might be within the pleural cavity, and he had found, by the occasional introduction of an antiseptic which dissolved slowly within the cavity, that even where the discharge is fotid at the time of operation, it becomes quite sweet within a few days, never to resume its fotid character.

Mr. Thornley Stoker and Dr. Doyle also spoke. 


$$
y
$$

